on adipose tissue development were studied. At weaning, tricaprylin ingestion decreased fat content of the carcasses from 20.5 to $17.2 \%$. All of the adipose tissues were individually affected to about the same degree. When lambs weaned at 35 days were slaughtered, tricaprylin led to an indirect effect as opposed to its effect at weaning; fat content of the carcasses increased (non-significantly) from 24.8 to $26.2 \%$. With lambs weaned when 45 days old, the opposite effect was obtained: fat content of the carcasses decreased significantly from 29.6 to $26.6 \%$. This difference might be explained by the significant increase in the proportion of adipose tissues in the carcasses of lambs fed the conventional milk replacer (from 24.8 to $29.6 \%$, according to age at weaning) mostly resulting from an increase of intermuscular fat in those lambs.

In both cases (weaning at 35 or at 45 days), the type of milk given before weaning does not change inner fat. Tentative multivariate analysis shows variations of the long-term effect of tricaprylin or conventional fat with genetic type, type of breeding (single, double or triple) rate of growth before or after weaning. It is concluded that it is not possible now to further improve the carcass quality of lambs by the type of milk replacer, but that analysis of the unfavorable effects observed opens the way to new possibilities.

\title{
Use of lactose and urea in the diet of the fattening lamb at weaning
}

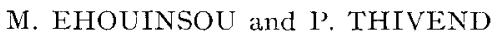 \\ Station de Recherches sur l'Elevage des Ruminants, \\ Centre de Recherches de Clermont-Ferrand, I.N.R.A., Theix, 63 IIo Beaumont
}

This report studies the utilisation of lactose and urea in feed for fattening lambs. Four

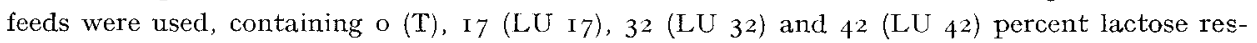
pectively in the form of ultrafiltrated whey. These fecds contained the same quantities of soyabean meal, lucerne and straw and $\mathrm{r} .5, \mathrm{~T}, 2.4$ and $2.7 \%$ urea (Table I). They were given to $4^{2}$ weaned lambs weighing about $20 \mathrm{~kg}$ at the beginning of the experiment. The animals were fed so that they received the same amounts of gross energy and nitrogen. Animal growth rate and the feed efficiency of different diets were measured. Animals were usually slaughtered at $35 \mathrm{~kg}$; the carcass composition (muscle, fat, bone) was determined and, using the difference with the animal carcass at the beginning of the experiment, gains in carcass weight and in different tissues were calculated.

The presence of lactose and urea in the feed slightly improved animal liveweight gain and feed efficiency of the ration (Table 2). Dressing percentage was greatly increased (from 3 to $5 \%$ ) (Table 3 ) and carcass composition highly modified (Table 4). Lambs receiving lactose formed more muscle, but with the same quantities of fat as those of the control group. A change in rumen fermentation by increasing butyric and propionic acid production, and the very good utilisation of non-protein nitrogen by rumen microflora might account for the better use for growth of the end-products resulting from digestion of lactose containing diets. 